\title{
Masks for the public: laying straw men to rest
}

\author{
Trisha Greenhalgh ${ }^{1}$ \\ ${ }^{1}$ University of Oxford
}

May 18, 2020

\begin{abstract}
This paper responds to one by Graham Martin and colleagues, who offered a critique of my previous publications on masks for the lay public in the Covid-19 pandemic. I address their charges that my co-authors and I had misapplied the precautionary principle; drawn conclusions that were not supported by empirical research; and failed to take account of potential harms. But before that, I remind Martin et al that the evidence on mask wearing goes beyond the contested trials and observational studies they place centre stage. I set out some key findings from basic science, epidemiology, mathematical modelling, case studies and natural experiments, and use this rich and diverse body of evidence as the backdrop for my rebuttal of their narrowly-framed objections. I challenge my critics' apparent assumption that a particular kind of systematic review should be valorised over narrative and real-world evidence, since stories are crucial to both our scientific understanding and our moral imagination. I conclude by thanking my academic adversaries for the intellectual sparring match, but exhort them to remember our professional accountability to a society in crisis. It is time to lay straw men to rest and engage, scientifically and morally, with the dreadful tragedy that is unfolding across the world.
\end{abstract}

\section{Introduction}

Since the Covid-19 pandemic emerged, I have co-authored several articles in both the academic and lay literature supporting the wearing of face masks by the general public. ${ }^{1-3}$ In response to negative criticism on social media, I put out a challenge: either write a point by point critique of my papers or back off. Graham Martin and colleagues responded with a preprint paper ${ }^{4}$ and a rapid BMJ response. ${ }^{5}$

Later in this article, I will address their substantive scientific points, which I will number and put in italics. I have tried to represent their points faithfully, without exaggeration, and apologise in advance if I have not captured their intended nuances. But first, let me highlight a subtle rhetorical move by Martin et al: they completely ignore various types of evidence - including basic science, mathematical modelling and real-world case examples of asymptomatic transmission and super-spreader events. Before addressing what they did talk about in their paper, ${ }^{4}$ I set out some important scientific evidence that they did not talk about. I draw heavily on the primary sources cited in the narrative review by Howard et al. ${ }^{6}$

\section{A wider evidence base}

The basic science of Covid-19 is important. The Sars-CoV-2 virus which causes this disease replicates in the upper respiratory tract (in contrast to the causative agent of Sars-CoV-1, which is a less contagious lower respiratory tract virus). ${ }^{78}$ This means it is likely to be transmitted mainly by droplets (which is why there is so much emphasis on hand-washing, since droplets contaminate surfaces). Droplets emitted from the human respiratory tract (which are relatively large) quickly turn into aerosols (smaller micro-droplets), ${ }^{9}$ so unless they are controlled at source, they become harder to block. 
A crucially important point, which is often overlooked by doctors, systematic reviewers and the lay press (and which was not addressed at all by Martin et al), is that most research on masks - almost all of which has been undertaken in the context of healthcare workers - considers the extent to which they protect the wearer. The current question we need to address is a different one: whether mask wearing protects other people from droplets emitted by the wearer- a measure known as source control. Source control works in a different way to wearer-protection - by blocking large droplets as they are emitted in coughing, sneezing and talking and before they become aerosolised. ${ }^{10-12}$ Large droplets (and indeed a proportion of aerosols) are blocked - not perfectly, but significantly - by cotton home-made masks. ${ }^{13-16}$

Masks that protect the wearer work by blocking tiny aerosolised particles. For this reason, medical-grade masks need to meet stringent filtration standards, about which much has been written (see for example ${ }^{17}$ ). In contrast, source control masks can potentially be very effective even if they only block the larger droplet particles. Studies of the efficacy of masks in protecting the wearer are therefore irrelevant to the question of source control.

Evidence of asymptomatic carriage of Sars-CoV-2 is strong and consistent. Oran and Topol have analysed (to date) 12 such examples from around the world, ${ }^{18}$ including cohorts identified for nationwide testing (Iceland), local population testing (Vo, Italy), passengers or crew of three ships (Diamond Princess, USS Theodore Roosevelt and Charles de Gaulle aircraft carrier), nursing home staff and residents (USA), residents of two homeless shelters (Boston and Los Angeles), ex-pats (Japanese evacuated from Wuhan and Greek citizens evacuated from other countries), and pregnant women (New York City obstetric patients). In these diverse cohorts, between $31 \%$ and $88 \%$ of positive cases were asymptomatic or pre-symptomatic when tested. A recent editorial in the New England Journal of Medicine argued that the exceptionally high rates of asymptomatic transmission of Sars-CoV-2 call for a different approach to infection control - specifically, masks for the public. ${ }^{19}$

In contrast to the high transmission rates from such individuals in this case series, there are some impressive case examples of infected individuals not passing on the virus when wearing a mask. For example one man flew from China to Toronto wearing a mask for the entire flight, became symptomatic the next day and tested positive for covid-19; none of the other passengers or crew became infected. ${ }^{20}$

Another piece of evidence that masks could make a big difference is super-spreader events, a list of which has been compiled by Kay. ${ }^{18}$ Perhaps the most dramatic is the choir practice in Seattle, in which, despite maintaining a degree of social distancing during the rehearsal, 45 of 60 people became infected and two (so far) have died. ${ }^{21}$ In all these super-spreader events, extensive transmission was traced back to close contact - but not necessarily physical touching. As the authors put it: "When do COVID-19 [super-spreader events] happen? ... Wherever and whenever people are up in each other's faces, laughing, shouting, cheering, sobbing, singing, greeting, and praying."

In relation to a community-wide intervention such as mask-wearing, we do not need to prevent every transmission of every droplet or every viral particle. As with handwashing and social distancing, the objective of the policy is more modest: to achieve a substantial reduction in the transmission rate of the virus. Every infectious disease has a transmission rate $(\mathrm{R} 0)$. A disease with an $\mathrm{R} 0$ of 1.0 means that each infected person, on average, infects one other person. A disease whose R0 is less than 1.0 will die out. The strain of flu that caused the 1918 pandemic had an R0 of 1.8. The R0 of Sars-CoV-2 was estimated at 2.4 by Imperial College researchers, ${ }^{22}$ and other research suggests it could even higher. ${ }^{23}$ A population measure that reduces the transmission rate ("effective R0" or $\mathrm{R}_{\mathrm{eff}}$ ) to below 1.0 will be highly effective, even if some cases of transmission still occur .

Mathematical modelling suggests that a mask that is $60 \%$ effective at blocking viral transmission and is worn by $60 \%$ of the population will reduce R0 to below $1.0 .^{24}$ This leaves plenty of room for error as people make their own imperfect masks from old clothing and as some people either cannot or will not wear a mask. Not all respiratory viruses are filtered equally by face masks; masks appear to be more efficient at blocking Sars-Cov-2 than rhinoviruses, for example. ${ }^{25}$ Materials scientists have shown that whilst different fabrics are 
more or less efficient at blocking particle transmission, cotton weaves with high thread count or a double layer of two different fabrics (e.g. cotton-flannel) typically provides high filtration efficiency. ${ }^{26}$

There are now many natural experiments of mask-wearing in Covid-19, as countries introduce either mandatory or voluntary mask-wearing policies. Of note is the example of the Czech Republic and Austria, both of which introduced social distancing on the same day; the former also introduced compulsory mask wearing. New covid-19 infections fell more quickly in the Czech Republic, and only began to fall in Austria after masks were made mandatory two weeks later. ${ }^{3}$ Also noteworthy is the observation that every single country where mask-wearing has been introduced as national policy (often but not always alongside other measures), rates of transmission fell in the subsequent days.

All these various streams of evidence contribute, in different ways and at different levels, to strengthen the argument for mask wearing. With this wider evidentiary context sketched, let me now take on the specific claims made by Martin et al in their paper and rapid response: ${ }^{4}$

\section{Precautionary principle, "weak" evidence and potential harms}

The precautionary principle we invoked to justify wearing of masks ${ }^{1}$ is [Martin et al imply] irrelevant, because it is normally used to advise caution in the uptake of innovations with known benefits but uncertain or unmeasurable downsides, such as exposure of the public to radiation.

The term "precautionary principle" does not have a fixed meaning, though I accept that it is more usually invoked as described by Martin et al. It may surely prove equally appropriate a) when harm is not currently happening but a proposed intervention may cause harm and b) when serious harm is currently happening and a proposed intervention may reduce that harm. There seems to me to be a strong symmetry between these examples. One does not cancel the other out. Both the omission in the former case and the act in the latter case are measures aimed at preventing harm.

"[T]he very weak evidence for face masks should be reiterated". Trials have shown no evidence of reduced transmission with masks compared to no masks, and observational studies are contaminated with multiple confounders (e.g. parallel introduction of other measures such as hand washing).

The evidence base for face masks (described above) is not weak. However, it was a weak rhetorical move for Martin et al to ignore the strongest evidence when penning their critique. Our BMJ analysis article briefly reviewed the literature from experimental trials and systematic reviews. ${ }^{1}$ Two pre-print systematic reviews ${ }^{27} 28$ and a narrative review ${ }^{6}$ were all published the same week. In all those syntheses, there is a conspicuous absence of experimental evidence in relation to the wearing of masks in public places, by the lay public, as source control to prevent community transmissionof any respiratory illness.

The sum total of randomised trials and observational studies covered in these reviews, all of which are irrelevant to the question of source control, comprise: a) studies of mask-wearing within the home to reduce contagion to other family members; ${ }^{29-38}$ b) studies of occupational exposure (e.g. workers in poultry factories); $; 940$ c) studies of specific mass events (notably, pilgrimages to the Hajj); ${ }^{41-47}$ d) studies in schools and university halls of residence; $;^{48-51}$ e) studies of air travel $;{ }^{52} \mathrm{f}$ ) studies of healthcare workers; ${ }^{38}{ }^{53-55}$ and just two studies of general community prevention: an attempt to prevent the common cold in Finland, ${ }^{56}$ and a paper on behavioural measures (among other things) in the prevention of SARS, in which those who "always" wore a mask when outside the home had a relative risk of developing the disease of 0.3 compared to those who "never" wore one. ${ }^{57}$

All of these primary studies were designed to test the hypothesis that wearing a mask in the specific situation described in (a) to (g) aboveprotects the wearer. The question my colleagues and I have addressed in our articles $^{1-3}$ was a completely different one: whether mask wearing by a member of the general publicprotects others in the community. Martin et al's depiction of the evidence from trials and observational cohort studies as "very weak" is incorrect. Such randomised controlled trial evidence, in relation to source control, 
is entirely absent and unrelated evidence should not be presented as a possible answer. (Note: this does not mean there is no evidence at all - merely, that there is no evidence valued by the RCT community).

Absence of trial evidence is partly due to the fact that experimental studies of mass public health measures are usually impractical. We don't randomise schools to close, towns to go into lockdown, people to sneeze into their elbows or whole communities to wash their hands regularly. That is simply not how mass public health interventions get tested. The argument that we should not recommend masks because there are no published experiments is out of step with other public health policy on infection control in general and covid19 in particular. As with other public health measures, we should make a decision based on an assessment of the full body of evidence described above.

Wearing face masks may cause harm, specifically [citing the Jefferson systematic review28] "discomfort, dehydration, facial dermatitis, distress, headaches, exhaustion".

It is widely reported that prolonged use of personal protective equipment by healthcare personnel in pandemic contexts is associated with all the problems listed (though exhaustion in particular may have other explanations in such circumstances). Some research studies have confirmed that prolonged wearing of medical-grade masks by healthcare workers can result in physical and psychological harms. ${ }^{58-61}$ However, neither Martin et al nor the Jefferson systematic review which they cite offer any evidence whatsoever that the use of homemade cloth masks by the lay public for source control has been shown to cause such harms. Indeed, there is no common-sense reason why a mask made out of one's own old t-shirt would cause illness when the t-shirt itself was well tolerated (and if it wasn't, why make a mask out of it?). The possible irritant effect of a mask should also be weighed against its potential benefit.

\section{Can the general public be trusted?}

The general public are unlikely to use masks "properly". Even healthcare workers struggle to achieve necessary standards of donning and doffing technique, and "inappropriately discarded masks present an infection risk".

Infection control standards designed for healthcare workers are irrelevant to the general public. The infected particles on a healthcare worker's mask are likely to come from patients, whereas the mask wearer is (hopefully) uninfected and therefore vulnerable. In contrast, if a member of the public is wearing a cloth mask, they are most likely source of any infection on their own mask. The more infectious particles that are caught in that mask, the fewer will have been aerosolised to infect others. A mask that has been removed does not need to be disinfected, and formal doffing is not needed (though hand-washing would be sensible in case the mask is contaminated with droplets from others). Sars-CoV-2 has a lipid membrane which is destroyed by soap or detergent (this, of course, is why hand-washing works). A cloth mask can be laundered along with other clothing in a normal hot wash. ${ }^{62}$ An alternative option in low-income countries is to wash the mask with soap and water and leave it to dry in the sun. Imposing unnecessarily high standards of disinfection on the public is likely to reduce the uptake of the measure and be counterproductive.

Being able to make, don, doff and disinfect your own cloth mask is a middle-class privilege. The efficacy of masks in the general population will be reduced by "the potential for great variation in materials, fit, adherence, touching and adjustment, doffing, disposal, frequency of laundering and so on".

There is no need to standardise the design of masks or fetishise how they are worn, any more than we do so for shoes to protect our feet. Cotton and similar materials do not block droplets entirely - but most double-layer fabrics seem to filter more than $90 \%$ of them. ${ }^{13-16}$ As noted above, if $60 \%$ of people wear a mask that is $60 \%$ effective, this is likely to be sufficient to substantially reduce the transmission of Sars$\mathrm{CoV}-2$. To say that because some people may find it difficult to obtain or launder a mask, we should not recommend them for anyone is illogical - especially since adverse socio-economic circumstances is a risk factor for developing Covid-19 and also for poorer prognosis. ${ }^{63}$ The negative, individualist emphasis of Martin et al's critique ignores the positive impact of mask-making initiatives as a component of wider community 
resilience strategies in Covid-19. ${ }^{64}$ The South African Government, for example, has recently issued a tender for community sewing co-operatives to supply cloth face masks. ${ }^{65}$

Risk compensation (in which people made to wear masks reduced other infection control behaviours such as hand-washing) could occur

Martin et al cite a review from 20 years ago which describes mixed findings on risk compensation behaviours. ${ }^{66}$ They fail to cite a more recent review suggesting that such behaviours appear rare. ${ }^{67}$ Both these reviews, however, focused mainly on injury prevention, not on infection control measures. More relevant perhaps are studies showing that teenagers vaccinated against human papilloma virus do not appear to take more sexual risks, ${ }^{68} 69$ though there is some evidence that pre-exposure prophylaxis may increase sexual risk-taking in men who have sex with men. ${ }^{70}$ The argument that risk compensation behaviour would occur specifically in relation to masks in the context of Covid-19 is entirely speculative. It is also unlikely. If adverse behaviour change happens to a significant degree, we would surely have seen some examples from around the world by now, since dozens of countries have now made mask-wearing mandatory.

\section{Unintended consequences?}

"[U]niversal mask-wearing might aggravate the climate of fear already documented for Covid-19"

Fear is perhaps a reasonable response to a deadly pandemic that has so far affected at least three million people and cost hundreds of thousands of lives. There is no evidence whatsoever that mask-wearing policies increase fear. The counter-argument - that such a measure would help reduce fear - is equally plausible (though there is no actual evidence either way). In studies of community mask use in tuberculosis control, mask-wearing by affected individuals reduced disease transmission but increased stigma, ${ }^{71}{ }^{72}$ whereas promotion of mask-wearing by all members of the community was associated with destigmatisation. ${ }^{72}$ The relevance of these findings to the current pandemic are unclear.

Promoting mask-wearing by the lay public could lead to a shortage of medical-grade masks.

This is a real concern, but it is not a reason to distort or deny the evidence of benefit. There is no reason why the public should wear medical-grade masks, since cotton masks are more comfortable, recyclable and sufficiently effective for source control. I accept that a public information campaign would be needed to get this message across to lay people as well as to clinicians and scientists (most of whom, like Martin et al, have unjustifiable extrapolated findings from research on infection control in healthcare settings and sought to apply the same standards to the public). In any case, simple surgical masks could be produced easily and in large numbers by repurposing manufacturing capacity if the political will was there. ${ }^{73}$

"[B]usinesses or states might see widespread or mandatory mask-wearing as a warrant for a premature return to 'business as usual', justifying unsafe workplaces or crowded commuting conditions in terms of the protection offered by masks."

This statement is entirely speculative. No evidence is given for it and it implies that the preferred state is for society to remain in lockdown indefinitely. The risks to the economy of prolonged lockdown are dire. ${ }^{74} 75$ Recession and job losses will have a disproportionate effect on the poor and socially excluded. There are ethical as well as scientific arguments for considering all measures that may help to reduce the lockdown period and get businesses up and running as a matter of urgency.

Masks are an example of a complex intervention in a complex system. Their effects are impossible to predict, therefore we should not introduce them.

The papers cited to support this assertion (one of which was co-authored by me ${ }^{76}$ ) actually support the opposite conclusion. Just because a complex system is unpredictable does not mean we should do nothing. ${ }^{77}$ As Martin et al acknowledge, careful data collection and frequent, timely analysis that feeds into adjustment of policy will allow an adaptive and data-driven response. Their depiction of current UK policy as too 
"blunt" to respond in this way is conflating politics with science. It is not an argument to sit idle when hundreds are dying daily.

\section{"Systematic" versus narrative reviews}

In the first paragraph of their paper, Martin et al contrast "two [preprint] systematic reviews" with "another preprint review, with more opaque methods but encompassing an eclectic range of disciplinary perspectives". The implication is that the conclusions of "systematic" reviews which favour controlled experiments are necessarily more reliable than those of "opaque" and "eclectic" narrative reviews which bring in so-called anecdotal evidence and arguments from basic and social sciences. Elsewhere, colleagues and I have challenged this conceptual bias. ${ }^{78}$ In that paper, we distinguish between narrowly-defined biomedical questions that can be answered using conventional systematic review, with meta-analysis where appropriate, and more complex, multifaceted problems that requireclarification and insight, for which a more interpretive and discursive synthesis of is needed.

Looking back at the first part of this paper, where I summarised the evidence that Martin et al chose to ignore, I am struck by how they dismissed the stories (the Covid-stricken choir, the air passenger whose mask may have saved a plane-load of people from contagion, the cruise ships that became floating quarantine prisons). But these stories are crucial to both our scientific understanding and our moral imagination. Their contrasting plots - tragedy, melodrama, lucky escape - pull together complex chains of influence and remind us that causality in a pandemic is rarely linear. Anecdote may be a low form of evidence in some taxonomies, but each one calls for an explanation.

As my co-authors and I concluded in out article on narrative review:

"Training in systematic reviews has produced a generation of scholars who are skilled in the technical tasks of searching, sorting, checking against inclusion criteria, tabulating extracted data and generating 'grand means' and confidence intervals. These skills are important, but ... critics may incorrectly assume that they override and make redundant the generation of understanding. ... While there are occasions when systematic review is the ideal approach to answering specific forms of questions, the absence of thoughtful, interpretive critical reflection can render such products hollow, misleading and potentially harmful." 78

\section{Conclusion}

In conclusion, I congratulate Martin et al for rising to my challenge to produce a critique of my publications on face masks for the public. But whilst academic sparring can keep a few sociologists amused during lockdown, we also need to remember our moral accountability to a society in crisis. I myself trained as a doctor. The relentless, day on day stories of avoidable deaths from this dreadful disease sicken me. I will do whatever I can, as an academic, a doctor and a citizen, to reduce that death toll and help get society back running again.

As Gandhi et al concluded in their NEJM editorial: "This unprecedented pandemic calls for unprecedented measures to achieve its ultimate defeat".${ }^{19}$ It is time to put the straw men to rest and take a less mischievous perspective on the evidence.

\section{Acknowledgements}

Thanks to Helene-Mari van der Westhuizen for helpful comments on an earlier draft, and to co-authors of my earlier papers (Manuel Schmid, Thomas Czypionka, Dirk Bassler, Laurence Gruer, Jeremy Howard, Zeynep Tufekci) and Babak Javid for ideas and inspiration. I acknowledge funding from the Wellcome Trust (WT104830MA) and UK National Institute for Health Research (BRC-1215-20008). Responsibility for this article is mine alone. 


\section{References}

1. Greenhalgh T, Schmid MB, Czypionka T, et al. Face masks for the public during the covid-19 crisis. Bmj 2020;369:m1435. doi: 10.1136/bmj.m1435 [published Online First: 2020/04/11]

2. Tufekci Z, Howard J, Greenhalgh T. The real reason to wear a mask. The Atlantic 2020;22nd April 2020. Accessed 27th April 2020 at https://www.theatlantic.com/health/archive/2020/04/dont-wear-maskyourself/610336/

3. Greenhalgh T, Howard J. Masks for all? The science says yes. (blog).fastai 2020;Accessed 27th April 2020 at https://www.fast.ai/2020/04/13/masks-summary/

4. Martin G, Hanna E, Dingwall R. Face masks for the public during Covid19: an appeal for caution in policy. Preprint Accessed 27th April 2020 at https://wwwdoradmuacuk/bitstream/handle/2086/19526/Face\%20masks\%20caution\%20in\%20policy_v1_2020-04-22\%20\%28with\%20disclaimers\%29pdf 2020

5. Martin G, Hanna E, Dingwall R. Response to Greenhalgh et al.BMJ rapid responses Accessed 27th April 2020 at https://wwwbmjcom/content/369/bmjm1435/rr-432020

6. Howard J, Huang A, Li Z, et al. Face masks against COVID-19: an evidence review. Preprints 2020;Accessed 27th April 2020 at https://www.preprints.org/manuscript/202004.0203/v1

7. van Doremalen N, Bushmaker T, Morris DH, et al. Aerosol and surface stability of SARS-CoV-2 as compared with SARS-CoV-1. New England Journal of Medicine 2020 doi: 10.1056/NEJMc2004973

8. Wölfel R, Corman VM, Guggemos W, et al. Virological assessment of hospitalized patients with COVID2019. Nature 2020:1-10.

9. PAPINENI RS, ROSENTHAL FS. The size distribution of droplets in the exhaled breath of healthy human subjects. Journal of Aerosol Medicine 1997;10(2):105-16.

10. Bourouiba L. Turbulent gas clouds and respiratory pathogen emissions: potential implications for reducing transmission of COVID-19.Jama 2020

11. Duguid J. The size and the duration of air-carriage of respiratory droplets and droplet-nuclei. Epidemiology \& Infection 1946;44(6):471-79.

12. Morawska L, Johnson G, Ristovski Z, et al. Size distribution and sites of origin of droplets expelled from the human respiratory tract during expiratory activities. Journal of Aerosol Science2009;40(3):256-69.

13. Davies A, Thompson K-A, Giri K, et al. Testing the efficacy of homemade masks: would they protect in an influenza pandemic?Disaster medicine and public health preparedness2013;7(4):413-18.

14. Rengasamy S, Eimer B, Shaffer RE. Simple respiratory protection - evaluation of the filtration performance of cloth masks and common fabric materials against 20-1000 nm size particles. Annals of occupational hygiene 2010;54(7):789-98.

15. van der Sande M, Teunis P, Sabel R. Professional and home-made face masks reduce exposure to respiratory infections among the general population. PLoS One 2008;3(7)

16. Dato VM, Hostler D, Hahn ME. Simple Respiratory Mask: Simple Respiratory Mask. Emerging Infectious Diseases 2006;12(6):1033. 
17. Oberg T, Brosseau LM. Surgical mask filter and fit performance.American journal of infection control 2008;36(4):276-82.

18. Kay J. COVID-19 superspreader events in 28 countries: critical patterns and lessons. Quillette 2020;23rd April

19. Gandhi M, Yokoe DS, Havlir DV. Asymptomatic Transmission, the Achilles' Heel of Current Strategies to Control Covid-19: Mass Medical Soc, 2020.

20. Schwartz KL, Murti M, Finkelstein M, et al. Lack of COVID-19 transmission on an international flight. CMAJ2020;192(15):E410-E10.

21. Read R. A choir decided to go ahead with rehearsal. Now dozens of members have COVID19 and two are dead. Los Angeles Times2020;29th March 2020. Accessed 27th April 2020 at https://www.latimes.com/world-nation/story/2020-03-29/coronavirus-choir-outbreak

22. Ferguson N, Laydon D, Nedjati Gilani G, et al. Report 9: Impact of non-pharmaceutical interventions (NPIs) to reduce COVID19 mortality and healthcare demand. 2020

23. Liu Y, Gayle AA, Wilder-Smith A, et al. The reproductive number of COVID-19 is higher compared to SARS coronavirus. Journal of travel medicine 2020;27:taaa021.

24. Tian L, Li X, Qi F, et al. Calibrated Intervention and Containment of the COVID-19 Pandemic (preprint). arXiv:200307353v4 Accessed 27th April 2020 at https://arxivorg/pdf/200307353pdf 2020

25. Leung NH, Chu DK, Shiu EY, et al. Respiratory virus shedding in exhaled breath and efficacy of face masks. Nature Medicine2020:1-5.

26. Konda A, Prakash A, Moss GA, et al. Aerosol Filtration Efficiency of Common Fabrics Used in Respiratory Cloth Masks. ACS Nano 2020 doi: 10.1021/acsnano.0c03252

27. Brainard JS, Jones N, Lake I, et al. Facemasks and similar barriers to prevent respiratory illness such as COVID-19: A rapid systematic review. MedRxiv 2020. Accessed 12.4.20 at https://www.medrxiv.org/content/10.1101/2020.04.01.20049528v1.abstract;Preprint published online 6th April 2020 doi: https://doi.org/10.1101/2020.04.01.20049528

28. Jefferson $\mathrm{T}$, Jones $\mathrm{M}, \mathrm{Al}$ Ansari LA, et al. Physical interventions to interrupt or reduce the spread of respiratory viruses. Part 1-Face masks, eye protection and person distancing: systematic review and meta-analysis. medRxiv 2020. Accessed 9th Aprill 2020 at https://www.medrxiv.org/content/10.1101/2020.03.30.20047217v2

29. Cowling BJ, Fung RO, Cheng CK, et al. Preliminary findings of a randomized trial of non-pharmaceutical interventions to prevent influenza transmission in households. PLoS One 2008;3(5):e2101. doi: 10.1371/journal.pone.0002101 [published Online First: 2008/05/08]

30. Cowling BJ, Chan KH, Fang VJ, et al. Facemasks and hand hygiene to prevent influenza transmission in households: a cluster randomized trial. Ann Intern Med 2009;151(7):437-46. doi: 10.7326/0003-4819-1517-200910060-00142 [published Online First: 2009/08/05]

31. MacIntyre CR, Zhang Y, Chughtai AA, et al. Cluster randomised controlled trial to examine medical mask use as source control for people with respiratory illness. BMJ Open 2016;6(12):e012330. doi: 10.1136/bmjopen-2016-012330 [published Online First: 2017/01/01]

32. Suess T, Remschmidt C, Schink SB, et al. The role of facemasks and hand hygiene in the prevention of influenza transmission in households: results from a cluster randomised trial; Berlin, Germany, 20092011.BMC infectious diseases 2012;12(1):26.

33. Canini L, Andreoletti L, Ferrari P, et al. Surgical mask to prevent influenza transmission in households: a cluster randomized trial.PLoS One 2010;5(11):e13998. doi: 10.1371/journal.pone.0013998 [published Online 
First: $2010 / 11 / 26]$

34. Larson EL, Ferng Y-H, Wong-McLoughlin J, et al. Impact of non-pharmaceutical interventions on URIs and influenza in crowded, urban households. Public Health Reports 2010;125(2):178-91.

35. MacIntyre CR, Cauchemez S, Dwyer DE, et al. Face mask use and control of respiratory virus transmission in households. Emerging infectious diseases 2009;15(2):233.

36. Barasheed O, Alfelali M, Mushta S, et al. Uptake and effectiveness of facemask against respiratory infections at mass gatherings: a systematic review. Int $J$ Infect Dis 2016;47:105-11. doi: 10.1016/j.ijid.2016.03.023 [published Online First: 2016/04/06]

37. Simmerman JM, Suntarattiwong P, Levy J, et al. Findings from a household randomized controlled trial of hand washing and face masks to reduce influenza transmission in Bangkok, Thailand. Influenza Other Respir Viruses 2011;5(4):256-67. doi: 10.1111/j.1750-2659.2011.00205.x [published Online First: 2011/06/10]

38. Lau JT, Lau M, Kim JH, et al. Probable secondary infections in households of SARS patients in Hong Kong. Emerging infectious diseases 2004;10(2):236.

39. Jolie R, Backstrom L, Thomas C. Health problems in veterinary students after visiting a commercial swine farm. Can J Vet Res1998;62(1):44-8. [published Online First: 1998/01/27]

40. Tahir MF, Abbas MA, Ghafoor T, et al. Seroprevalence and risk factors of avian influenza H9 virus among poultry professionals in Rawalpindi, Pakistan. J Infect Public Health 2020;13(3):414-17. doi: 10.1016/j.jiph.2020.02.030 [published Online First: 2020/03/08]

41. Al-Jasser FS, Kabbash IA, Almazroa MA, et al. Patterns of diseases and preventive measures among domestic hajjis from Central, Saudi Arabia. Saudi Med J 2012;33(8):879-86. [published Online First: 2012/08/14]

42. Choudhry AJ, Al-Mudaimegh KS, Turkistani AM, et al. Hajj-associated acute respiratory infection among hajjis from Riyadh. East Mediterr Health $J$ 2006;12(3-4):300-9. [published Online First: 2006/10/14]

43. Alfelali M, Haworth EA, Barasheed O, et al. Facemask versus No Facemask in Preventing Viral Respiratory Infections During Hajj: A Cluster Randomised Open Label Trial. 2019

44. Balaban V, Stauffer WM, Hammad A, et al. Protective practices and respiratory illness among US travelers to the 2009 Hajj. Journal of travel medicine 2012;19(3):163-68.

45. Deris ZZ, Hasan H, Sulaiman SA, et al. The prevalence of acute respiratory symptoms and role of protective measures among Malaysian hajj pilgrims. J Travel Med 2010;17(2):82-8. doi: 10.1111/j.17088305.2009.00384.x [published Online First: 2010/04/24]

46. Emamian MH, Hassani AM, Fateh M. Respiratory tract infections and its preventive measures among Hajj pilgrims, 2010: a nested case control study. International journal of preventive medicine 2013;4(9):1030.

47. THE ROLE OF USING MASKS TO REDUCE ACUTE UPPER RESPIRATORY TRACT INFECTIONS IN PILGRIMS. 4th Asia Pacific travel health conference, Shanghai, PR China; 2002.

48. Aiello AE, Murray GF, Perez V, et al. Mask use, hand hygiene, and seasonal influenza-like illness among young adults: a randomized intervention trial. J Infect Dis 2010;201(4):491-8. doi: 10.1086/650396 [published Online First: 2010/01/22]

49. Aiello AE, Perez V, Coulborn RM, et al. Facemasks, hand hygiene, and influenza among young adults: a randomized intervention trial.PLoS One 2012;7(1):e29744. doi: 10.1371/journal.pone.0029744 [published Online First: 2012/02/02]

50. Kim CO, Nam CM, Lee DC, et al. Is abdominal obesity associated with the 2009 influenza A (H1N1) pandemic in Korean school-aged children? Influenza Other Respir Viruses 2012;6(5):313-7. doi: 10.1111/j.17502659.2011.00318.x [published Online First: 2011/12/14] 
51. Uchida M, Kaneko M, Hidaka Y, et al. Effectiveness of vaccination and wearing masks on seasonal influenza in Matsumoto City, Japan, in the 2014/2015 season: An observational study among all elementary schoolchildren. Prev Med Rep 2017;5:86-91. doi: 10.1016/j.pmedr.2016.12.002

52. Zhang L, Peng Z, Ou J, et al. Protection by Face Masks against Influenza A(H1N1)pdm09 Virus on Trans-Pacific Passenger Aircraft, 2009.Emerg Infect Dis 2013;19(9):1403-10. doi: 10.3201/eid1909.121765

53. Sung AD, Sung JA, Corbet K, et al. Surgical Mask Usage Reduces the Incidence of Parainfluenza Virus 3 in Recipients of Stem Cell Transplantation: American Society of Hematology, 2012.

54. Wu S, Ma C, Yang Z, et al. Hygiene behaviors associated with influenza-like illness among adults in Beijing, China: a large, population-based survey. PloS one 2016;11(2)

55. Lau JT, Tsui H, Lau M, et al. SARS transmission, risk factors, and prevention in Hong Kong. Emerging infectious diseases 2004;10(4):587.

56. Shin K, Wakabayashi H, Sugita C, et al. Effects of orally administered lactoferrin and lactoperoxidase on symptoms of the common cold. International journal of health sciences 2018;12(5):44.

57. Wu J, Xu F, Zhou W, et al. Risk factors for SARS among persons without known contact with SARS patients, Beijing, China. Emerging infectious diseases 2004;10(2):210.

58. Al Badri FM. Surgical mask contact dermatitis and epidemiology of contact dermatitis in healthcare workers. Current Allergy \& Clinical Immunology 2017;30(3):183-88.

59. Zuo Y, Hua W, Luo Y, et al. Skin Reactions of N95 masks and Medial Masks among Health Care Personnel: A self-report questionnaire survey in China. Contact Dermatitis 2020

60. Warshaw EM, Schlarbaum JP, Silverberg JI, et al. Safety equipment: When protection becomes a problem. Contact dermatitis2019;81(2):130-32.

61. Yan Y, Chen H, Chen L, et al. Consensus of Chinese experts on protection of skin and mucous membrane barrier for healthcare workers fighting against coronavirus disease 2019. Dermatologic Therapy2020:e13310.

62. (US) CfDCaP. Cleaning and disinfecting for households. Accessed 27th April 2020 at https://www.cdc.gov/coronavirus/2019-ncov/prevent-getting-sick/cleaning-disinfection.html?CDC_-

AA_refVal=https\%3A\%2F\%2Fwww.cdc.gov\%2Fcoronavirus\%2F2019-ncov\%2Fprepare\%2Fcleaningdisinfection.html. Atlanta: CDC 2020.

63. Organization WH. Coronavirus disease 2019 (COVID-19): situation report, 72. Geneva: WHO 2020.

64. Ngai R. Volunteering in a lockdown: A stay-at-home mask-making sewing bee. Microsoft News 2020;9th April. Accessed 27th April 2020 at https://news.microsoft.com/en-hk/2020/04/09/volunteeringin-a-lockdown-a-stay-at-home-mask-making-sewing-bee/

65. Anonymous. A call out to existing South African owned, registered and tax compliant smmes and cooperatives to submit information in the following categories Johannesberg, SA: South African Government, Department of Small Business Development. 2020. Accessed 27th April 2020 at http://www.dsbd.gov.za/wpcontent/uploads/2020/04/RFI-4-Request-For-Information-Fabric-Cloth-Face-Masks-13.04.-2020-Final.pdf.

66. Hedlund J. Risky business: safety regulations, risk compensation, and individual behavior. Injury prevention 2000;6(2):82-89.

67. Pless B. Risk compensation: Revisited and rebutted. Safety2016;2(3):16.

68. Kasting ML, Shapiro GK, Rosberger Z, et al. Tempest in a teapot: A systematic review of HPV vaccination and risk compensation research. Human vaccines $\mathscr{E}$ immunotherapeutics 2016;12(6):1435-50.

69. Madhivanan P, Pierre-Victor D, Mukherjee S, et al. Human Papillomavirus Vaccination and Sexual Disinhibition in Females: A Systematic Review. Am J Prev Med 2016;51(3):373-83. doi: 
10.1016/j.amepre.2016.03.015 [published Online First: 2016/05/01]

70. Traeger MW, Schroeder SE, Wright EJ, et al. Effects of Pre-exposure Prophylaxis for the Prevention of Human Immunodeficiency Virus Infection on Sexual Risk Behavior in Men Who Have Sex With Men: A Systematic Review and Meta-analysis. Clin Infect Dis 2018;67(5):676-86. doi: 10.1093/cid/ciy182 [published Online First: 2018/03/07]

71. Joachim G, Acorn S. Stigma of visible and invisible chronic conditions. Journal of advanced nursing 2000;32(1):243-48.

72. Buregyeya E, Mitchell EM, Rutebemberwa E, et al. Acceptability of masking and patient separation to control nosocomial Tuberculosis in Uganda: a qualitative study. Journal of Public Health2012;20(6):599-606.

73. Reagan C. Retailers shift production to make masks, gowns for health-care workers in coronavirus pandemic. CNBC Online 26th March 2020. Accessed 1.4.20 at https://www.cnbc.com/2020/03/26/coronavirusretailers-make-masksgowns-for-healthcare-workers.html .

74. Doward J. Nearly seven million jobs at risk if lockdown lasts for months. Guardian 2020;19th April. Accessed 27th April 2020 at https://www.theguardian.com/world/2020/apr/19/nearly-seven-million-jobsat-risk-if-lockdown-lasts-for-months

75. Anonymous. Covid-19 causes Britain's fastest economic contraction on record. Economist 2020;19th April. Accessed 27th April 2020 at https://www.economist.com/britain/2020/04/11/covid-19-causesbritains-fastest-economic-contraction-on-record

76. Plsek PE, Greenhalgh T. Complexity science: The challenge of complexity in health care. $B M J$ 2001;323(7313):625-8. [published Online First: 2001/09/15]

77. Greenhalgh T, Papoutsi C. Studying complexity in health services research: desperately seeking an overdue paradigm shift: BioMed Central, 2018:95.

78. Greenhalgh T, Thorne S, Malterud K. Time to challenge the spurious hierarchy of systematic over narrative reviews? European journal of clinical investigation 2018;48(6):e12931. 